\title{
Molecular Characterization of Slow Leaf-Rusting Resistance in Wheat
}

\author{
Xiangyang Xu, Guihua Bai,* Brett F. Carver, Gregory E. Shaner, and Robert M. Hunger
}

\begin{abstract}
Slow leaf-rusting resistance in wheat (Triticum aestivum $\mathrm{L}$ ) is gaining acceptance as a breeding objective because of its durability in comparison with race-specific resistance. CI 13227 was previously reported to provide the highest level of slow leaf-rusting resistance. The objective of this study was to characterize the slow leaf-rusting resistance conferred by $\mathrm{CI} 13227$ using molecular markers. A population of recombinant inbred lines (RILs) derived from CI 13227/Suwon 92 was evaluated for final severity (FS), area under disease progress curve (AUDPC), infection rate (IR), and infection duration (ID) of leaf rust. Four hundred fifty-nine amplified fragment length polymorphism (AFLP) markers and 28 simple sequence repeat (SSR) markers were analyzed in the population. Two quantitative trait loci (QTL), designated as $Q L r$.osu- $2 B$ and $Q L r$.osu- $7 B L$, were consistently associated with AUDPC, FS, and IR of leaf rust, caused by Puccinia triticina (previously $P$. recondita Rob. Ex Desm. f. sp. tritici). The percentages of phenotypic variance explained by each QTL varied with experiments and traits, ranging from 13.4 to $18.8 \%$ for AUDPC, $\mathbf{1 2 . 5}$ to $\mathbf{2 0 . 8} \%$ for FS, and $\mathbf{1 2 . 9}$ to $\mathbf{1 6 . 1} \%$ for IR. The third QTL for leaf rust ID, designated as QLrid.osu-2DS, was located on chromosome 2DS and explained 26.4 and $21.47 \%$ of the phenotypic variance in 1994 and 1995, respectively. Both the QTL and correlation analysis indicate reasonable progress in leaf-rusting resistance by selecting for final severity. SSR markers closely associated with $Q L r . o s u-2 B$ or QLr.osu-7BL have potential to be used in marker-assisted selection (MAS) for durable leaf rust resistant cultivars.
\end{abstract}

TEAF RUST is one of the major wheat diseases worldwide. The short-lived nature of race-specific leaf rust resistance genes greatly compromises the efforts of breeders who use them, almost routinely, to breed resistant cultivars. Alternatively, a more durable form of resistance is attributed to slow leaf-rusting, for which certain genotypes have been identified and characterized (Caldwell et al., 1970; Kuhn et al., 1978; Shaner and Finney, 1980; Singh et al., 1998; Messmer et al., 2000). Methods used to assess slow leaf-rusting resistance include the severity measured either once at the peak of disease expression or several times during the course of disease in a growing season. The AUDPC has

X.-Y. Xu and B.F. Carver, Dep. of Plant and Soil Sciences, Oklahoma State Univ., Stillwater, OK 74078; G. Bai, USDA-ARS, Plant Science and Entomology Research Unit and Dep. of Agronomy, Kansas State Univ., Manhattan, KS 66506; G.E. Shaner, Dep. of Botany and Plant Pathology, Purdue Univ., West Lafayette, IN 47907; Robert M. Hunger, Dep. of Entomology and Plant Pathology, Oklahoma State Univ., Stillwater, OK 74078. A portion of this research was funded by the Oklahoma Wheat Research Foundation and the Oklahoma Agric. Exp. Stn. Mention of trade names or commercial products in this article is solely for the purpose of providing specific information and does not imply recommendation or endorsement by the U.S. Department of Agriculture. Received 29 June 2004. Genomics, Molecular Genetics \& Biotechnology. *Corresponding author (gbai@bear. agron.ksu.edu)

Published in Crop Sci. 45:758-765 (2005).

(c) Crop Science Society of America

677 S. Segoe Rd., Madison, WI 53711 USA been widely used to characterize foliar disease resistance (Jeger and Viljanen-Rollinson, 2001) because it reflects both severity and rate of disease development (Wilcoxson et al., 1975). IR and ID were also considered to be important factors of disease epidemics (Parlevliet, 1979).

Genetic studies indicated that slow leaf-rusting resistance is under polygenic control with moderately high heritability (Bjarko and Line, 1988a; Das et al., 1992). Additive gene effects are predominant for slow leafrusting, but additive $\times$ additive interactions have also been detected (Bjarko and Line, 1988b; Das et al., 1992). Therefore, slow-rusting resistance should be amenable to selection for improving resistance to leaf rust in winter wheat.

Two genes associated with slow leaf-rusting resistance have been identified, Lr34 (Dyck, 1977) and Lr46 (Singh et al., 1998). The Lr34 gene has been widely used in wheat breeding programs because of its durable resistance to leaf rust, its association with $Y r 18$, a stripe rust resistance gene, and its association with tolerance to Barley yellow dwarf virus infection (McIntosh, 1992; Singh, 1993). The combination of Lr34 with other genes, such as Lr12 and/or Lr13, provided durable leaf rust resistant cultivars worldwide (Roelfs, 1988), so not surprisingly, several attempts have been made to tag Lr34 with molecular markers.

Nelson et al. (1997a) found two loci associated with leaf rust resistance: one on $7 \mathrm{DS}$, the expected position of Lr34, and another on 2BS. Both loci cumulatively explained $45 \%$ of the phenotypic variance. William et al. (1997) identified three RAPD markers associated with leaf rust resistance using bulked segregant analysis (BSA). Two of them were located on 7BL and the third one hybridized to chromosome 1BS and 1DS. Faris et al. (1999) also found that a chromosome region on 7BL contributed to leaf rust resistance under natural infection. Messmer et al. (2000) detected six QTL for leaf rust resistance, and one major QTL on $7 \mathrm{BL}$ from the highly resistant parent Forno explained $35 \%$ of the phenotypic variance. Forno showed leaf tip necrosis. Because Lr34 was reported to be closely linked to the leaf tip necrosis gene, Ltn (Singh, 1992), the major rust resistance gene in Forno is likely Lr34. Schnursch et al. (2004) detected eight QTL for leaf rust resistance with two having major effects: one on 7DS and another on 1BS of Forno. Suenaga et al. (2003) identified a microsatellite marker close to Lr34.

In addition, another gene ( $\mathrm{Lr} 46$ ) for slow leaf-rusting resistance was identified on chromosome $1 \mathrm{~B}$ of the

Abbreviations: AFLP, amplified fragment length polymorphism; AUDPC, area under disease progress curve; FS, final severity; ID, infection duration; IR, infection rate; MAS, marker-assisted selection; QTL, quantitative trait loci; RILs, recombinant inbred lines; SSRs, simple sequence repeats. 
wheat cultivar Pavon 76 (Singh et al., 1998). William et al. (2003) identified two AFLP markers linked to Lr46 and located them on the distal end of the long arm of chromosome $1 \mathrm{~B}$.

Although slow-rusting resistance is durable, the pathogen may evolve to overcome it in agroecosystems. This "erosion of resistance" differs from the rapid breakdown in resistance conferred by major resistance genes (McDonald and Linde, 2002). Hence, alternative slow leaf-rusting resistance genes should be identified because it is reasonable to assume that isolates of Puccinia triticina with virulence to Lr34 or Lr46 may eventually appear and even dominate in the pathogen population. CI 13227 was identified as a different source of slow leaf-rusting and confers the highest level of resistance ever reported (Shaner and Finney, 1980; Shaner et al., 1997). Although pathogenic and genetic studies were conducted to investigate the effects of slow leafrusting resistance conferred by CI 13227 (Shaner and Finney, 1980; Shaner et al., 1997), characterization of these QTL using molecular markers has not been reported in this new source. The objectives of this study were to identify and locate QTL responsible for slow leaf-rusting resistance in CI 13227, and to develop molecular markers that can be used in MAS to facilitate improvement in durable leaf rust resistance.

\section{MATERIALS AND METHODS}

\section{Plant Materials}

A single-seed-descent population of 104 RILs was developed from the cross of CI 13227/Suwon 92. CI 13227 has a high level of slow-rusting resistance to wheat leaf rust and Suwon 92 is very susceptible to leaf rust (Shaner et al., 1997). The pedigree of CI 13227 is Wabash/American Banner//Klein Anniversario (Shaner et al., 1997). Suwon 92 derived from a cross between Suwon 85 and Suwon 13 (Shaner and Finney, 1980; Shaner et al., 1997). The 104 RILs and two parents were evaluated at the Agronomy Center for Research and Education, Purdue University, West Lafayette, IN, in 1994 and 1995 in a randomized complete-block design with two replications. Leaf rust severity was rated seven times in 1994 (from 29 May-19 June) and 1995 (from 30 May-25 June) according to the modified Cobb Scale (Peterson et al., 1948). As component traits of slow-rusting resistance, we calculated area under the disease progress curve (AUDPC) according to Shaner and Finney (1980). ID was defined as the length of the sporulating period and IR as daily disease progress rate (AUDPC/day). FS equaled the maximum severity during the course of rust infection.

\section{Analysis of Molecular Markers}

Genomic DNA was isolated from 2-wk-old wheat seedlings by the CTAB (cetyltrimethyllammonium) method (Murray and Thompson, 1980). To analyze AFLP, PstI and MseI were used as restriction enzymes for digestion of genomic DNA. PstI primers were labeled with infrared fluorescence dyes, and PCR products were separated in a LI-COR DNA Analyzer (LI-COR, Lincoln, NE) (Xu et al., 2005). A bulked segregant analysis (BSA, Michelmore et al., 1991) based on phenotypic evaluation was applied to screen informative AFLP primers. The resistant bulk contained equal amounts of DNA from five most resistant RILs with the lowest AUDPC and FS, and the susceptible bulk contained equal amounts of DNA from five most susceptible RILs with the highest AUDPC and FS. Among 612 Pst $\mathrm{I} / \mathrm{Mse}$ I primer pairs screened, 85 primer pairs showed polymorphism and subsequently were used to genotype the RILs. After 459 AFLP markers were evaluated in the population, three QTL were identified in the initial analysis. To determine the tentative chromosome locations of these QTL, a revised BSA method was used to screen a total of 240 SSR primers. Three pairs of bulks constrasting in the presence or absence of an individual QTL for leaf rust resistance were constructed based on AFLP markers flanking the target QTL. For each pair, the resistant bulk contained equal amounts of DNA from each of the five RILs that had AFLP alleles flanking a QTL for leaf rust resistance, and the susceptible bulk contained equal amounts of DNA from each of the five RILs that had alternative AFLP alleles. The selected RILs also showed extreme contrast in AUDPC and FS. Twenty-eight informative SSR primers which showed polymorphism between parents and at least one pair of bulks were used to screen the entire population of RILs. Protocol from Xu et al. (2005) was followed to develop SSR markers. The SSR markers were visualized by a silver staining method.

\section{Data Analysis}

One-way ANOVA was used to identify AFLP markers that were significantly associated with various component traits of slow-rusting resistance $(P<0.05)$. Genetic linkage maps were constructed with MapMaker 3.0 (Lander et al., 1987). A LOD threshold was set at 4.0 for the construction of linkage groups. Centimorgan (cM) values were calculated according to the Kosambi mapping function (Kosambi, 1944). Single marker analysis and interval analysis were performed by Qgene (Nelson, 1997b) to characterize the effects of each individual marker and to map the slow leaf-rusting QTL. The SAS procedure, GCHART, was used to generate histograms of phenotypic frequencies.

\section{RESULTS AND DISCUSSION}

\section{Segregation of Leaf Rust Resistance in RILs}

In both years, CI 13227 showed a higher level of slowrusting resistance to wheat leaf rust than Suwon 92, evidenced by lower AUDPC, FS, and IR (Table 1). Their progenies showed continuous distributions for AUDPC, FS, IR, and ID, varying from 27.9 to 548.7 for AUDPC, 11.5 to $87.5 \%$ for FS, 1.54 to 35.32 for IR, and 16.5 to $23.5 \mathrm{~d}$ for ID (Table 1 ). All traits revealed transgressive segregation in both years (Fig. 1), indicating their quantitative genetic nature.

Significant correlations $(P<0.01)$ were detected between years for AUDPC $(r=0.53)$, FS $(r=0.42)$, IR

Table 1. Area under disease progress curve (AUDPC), final severity (FS), infection rate (IR), and infection duration (ID) of CI13227, Suwon 92, and their RIL population $(n=104)$ in 1994 and 1995.

\begin{tabular}{lccccc}
\hline & Year & AUDPC & IR & FS (\%) & ID (d) \\
\hline CI 13227 & 1994 & 48 & 1.9 & 11.1 & $\mathbf{2 6 . 0}$ \\
& 1995 & 37 & 1.7 & 25.6 & $\mathbf{2 2 . 5}$ \\
Suwon 92 & 1994 & 464 & 23.5 & $\mathbf{7 6 . 0}$ & $\mathbf{1 9 . 5}$ \\
& 1995 & 335 & 15.3 & $\mathbf{6 9 . 0}$ & $\mathbf{1 8 . 0}$ \\
RIL means & 1994 & 306 & 13.6 & $\mathbf{5 2 . 1}$ & $\mathbf{2 2 . 7}$ \\
& 1995 & 235 & 12.7 & $\mathbf{5 6 . 1}$ & 19.7 \\
RIL ranges & 1994 & $\mathbf{3 3 - 6 6 7}$ & $\mathbf{1 . 3}-\mathbf{2 9 . 9}$ & $\mathbf{8 . 0 - 9 2 . 5}$ & $\mathbf{1 8 . 0 - 2 6 . 0}$ \\
& $\mathbf{1 9 9 5}$ & $\mathbf{2 2 - 4 2 8}$ & $\mathbf{1 . 0}-\mathbf{3 3 . 6}$ & $\mathbf{1 5 . 0 - 9 0 . 0}$ & $\mathbf{1 6 . 0 - 2 2 . 5}$ \\
\hline
\end{tabular}


A:

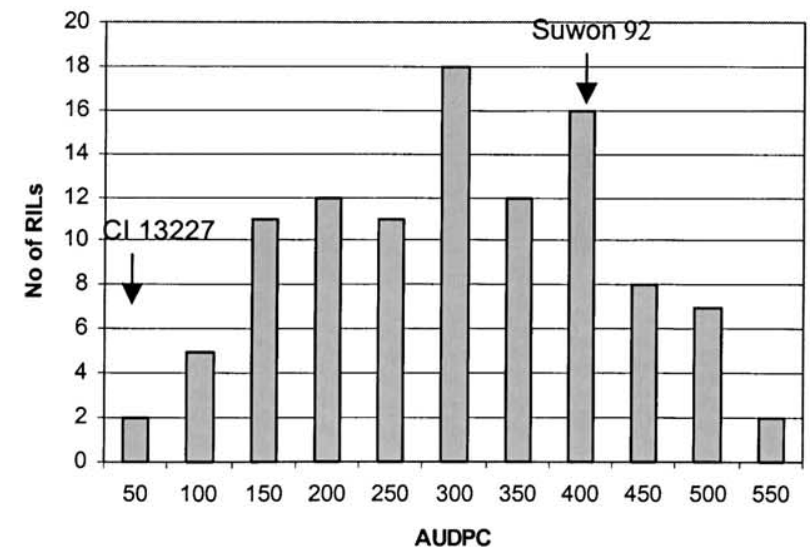

B:

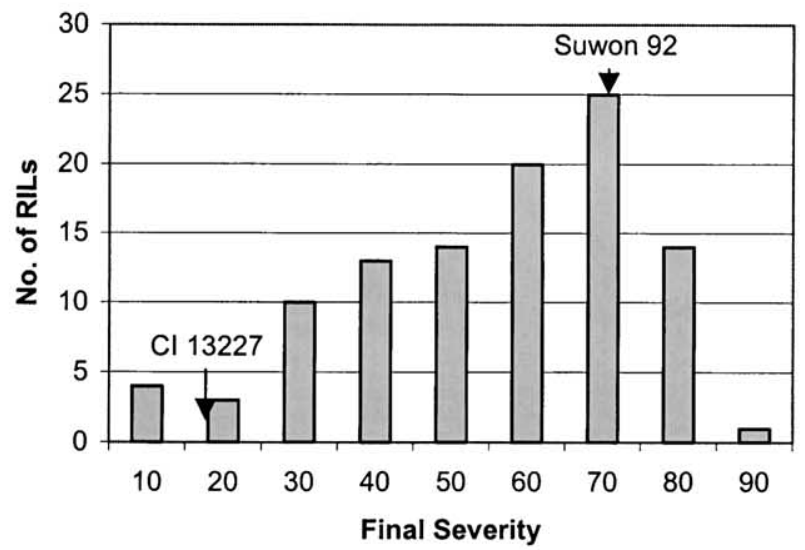

C:

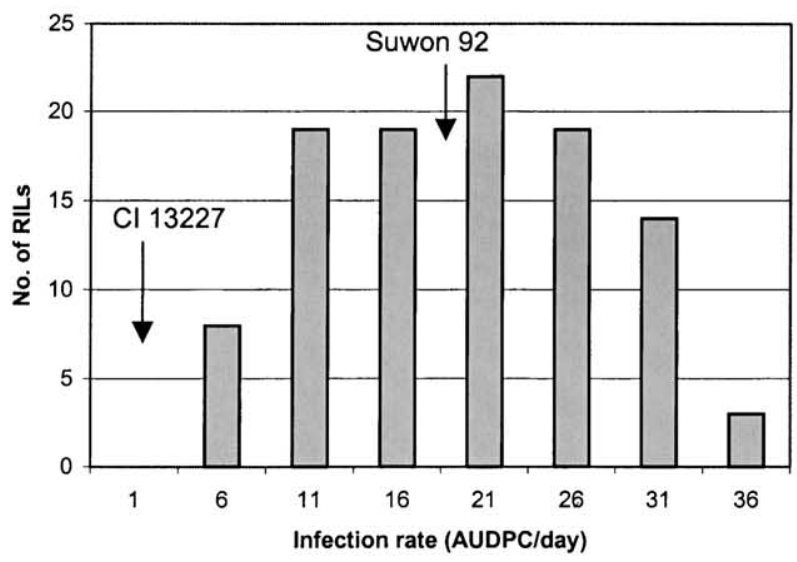

D:

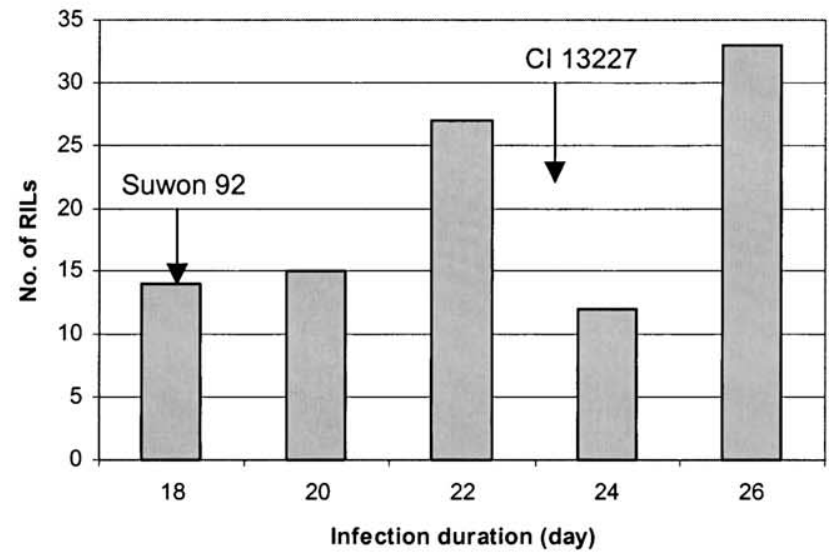

Fig. 1. Frequency distributions for AUDPC (A), FS (B), IR (C), and ID (D) measured across two experiments for 104 RILs derived from CI $13227 \times$ Suwon 92 and their parents.

$(r=0.63)$, and ID $(r=0.83)$. Correlation coefficients were high among AUDPC, FS, and IR, varying from 0.93 to 0.99 , indicating these traits may be under the same genetic control. ID was negatively correlated $(P<$ $0.01)$ with AUDPC, FS, and IR with correlation coefficients of $-0.64,-0.58$, and -0.72 , respectively.

\section{Single Marker Analysis}

Table 2 lists all molecular markers that were significantly associated with AUDPC, FS, or IR in both years. Twelve markers were significantly associated with all three traits. Linkage analysis showed that these markers belonged to two linkage groups, which were tentatively located on chromosome $2 \mathrm{~B}$ and the long arm of chromosome $7 \mathrm{~B}$, respectively, on the basis of the chromosomal locations of the SSR markers in each group. The determination coefficients of these markers varied from 3.9 to $19.4 \%$ for AUDPC, 5.8 to $19.0 \%$ for $\mathrm{FS}$, and 4.3 to $18.1 \%$ for IR in 1994, and 5.0 to $14.8 \%$ for AUDPC, 3.9 to $18.0 \%$ for FS, and 5.5 to $13.7 \%$ for IR in 1995 . The additive effects of these markers ranged from 25.4 to 58.3 for AUDPC, 3.9 to $8.5 \%$ for FS, and 1.4 to 2.7 for IR in 1994, and 21.7 to 35.4 for AUDPC, 3.4 to $7.0 \%$ for FS, and 1.4 to 2.2 for IR in 1995. In all cases higher values of AUDPC, FS, and IR were detected for the parental allele of Suwon 92. This suggested that resistance alleles conferring lower AUDPC, FS, and IR values came from CI 13227. All molecular markers linked to ID were located on chromosome 2D and were assigned to one linkage group (Table 3), spanning 45.3 $\mathrm{cM}$. Their determination coefficients ranged from 4.0 to $27.9 \%$ in 1994 , and 5.7 to $29.2 \%$ in 1995 , respectively. The additive effects of these markers ranged from 0.6 to $1.5 \mathrm{~d}$ in 1994 , and 0.4 to $0.9 \mathrm{~d}$ in 1995 , respectively.

\section{QTL Interval Analysis}

Interval mapping detected two QTL for AUDPC, FS, and IR in each year (Table 4), suggesting that at least 2 QTL contribute to slow leaf-rusting resistance in CI 13227. This is in agreement with previous reports based on biometric analysis (Das et al., 1992).

A QTL for AUDPC, FS, and IR, designated as QLr.osu-2B, was identified in both 1994 and 1995 (Fig. 2). $Q L$ r.osu- $2 B$ was tentatively located between AFLP marker XAGC.TGC135 and XCAG.CGAT70. This QTL appears to be close to the centromere because the linked 
Table 2. Mean allelic effects of significant molecular markers on chromosomes $2 B$ and $7 B L$ on area under disease progress curve (AUDPC), final severity (FS), and infection rate (IR) in the RIL population derived from CI 13227/Suwon 92 in 1994 and 1995.

\begin{tabular}{|c|c|c|c|c|c|c|c|c|c|c|c|c|c|c|}
\hline \multirow[b]{3}{*}{ Marker } & \multirow{3}{*}{$\begin{array}{c}\text { Chromosome } \\
\text { location }\end{array}$} & \multirow[b]{3}{*}{ Year } & \multicolumn{4}{|c|}{ AUDPC } & \multicolumn{4}{|c|}{ FS } & \multicolumn{4}{|c|}{ IR } \\
\hline & & & \multirow{2}{*}{$\begin{array}{c}R^{2} \\
(\%)\end{array}$} & \multicolumn{2}{|c|}{ Allele mean } & \multirow{2}{*}{$\begin{array}{c}\text { Additive } \\
\text { effect }\end{array}$} & \multirow{2}{*}{$\begin{array}{c}R^{2} \\
(\%)\end{array}$} & \multicolumn{2}{|c|}{ Allele mean } & \multirow{2}{*}{$\begin{array}{c}\text { Additive } \\
\text { effect }\end{array}$} & \multirow{2}{*}{$\begin{array}{c}R^{2} \\
(\%)\end{array}$} & \multicolumn{2}{|c|}{ Allele mean } & \multirow{2}{*}{$\begin{array}{c}\text { Additive } \\
\text { effect }\end{array}$} \\
\hline & & & & CI 13227 & Suwon 92 & & & CI 13227 & Suwon 92 & & & CI 13227 & Suwon 92 & \\
\hline \multirow[t]{2}{*}{ XCATG.ATGCGO } & 2B & 1994 & 19.4 & 244 & 358 & 57 & 16.2 & 44.4 & 59.6 & 7.6 & 16.5 & 11.1 & 16.2 & 2.5 \\
\hline & & 1995 & 13.3 & 202 & 269 & 34 & 14.8 & 50.4 & 63.2 & 6.4 & 13.7 & 12.2 & 16.5 & 2.2 \\
\hline \multirow[t]{2}{*}{ XTGC.ACAG198 } & 7BL & 1994 & 19.1 & 231 & 347 & 58 & 18.7 & 41.7 & 58.6 & 8.5 & 18.1 & 10.3 & 15.8 & 2.7 \\
\hline & & 1995 & 8.7 & 206 & 260 & 27 & 7.8 & 51.5 & 60.9 & 4.7 & 7.7 & 12.6 & 15.8 & 1.6 \\
\hline \multirow{2}{*}{ Xbarc18 } & 2B & 1994 & 17.0 & 251 & 356 & 53 & 13.5 & 45.7 & 59.3 & 6.8 & 14.8 & 11.4 & 16.1 & 2.4 \\
\hline & & 1995 & 11.9 & 203 & 267 & 32 & 13.6 & 50.4 & 62.6 & 6.1 & 11.9 & 12.3 & 16.4 & 2.0 \\
\hline \multirow{2}{*}{ ХАCA.CACG126 } & 7BL & 1994 & 16.3 & 350 & 250 & 50 & 19.0 & 44.0 & 60.2 & 8.1 & 13.7 & 11.3 & 15.8 & 2.2 \\
\hline & & 1995 & 13.4 & 269 & 201 & 34 & 10.4 & 51.0 & 61.9 & 5.5 & 11.0 & 12.3 & 16.2 & 1.9 \\
\hline \multirow{2}{*}{ XCATG.ATGC125 } & 7BL & 1994 & 15.3 & 255 & 357 & 51 & 18.9 & 44.6 & 61.0 & 8.2 & 14.6 & 11.5 & 16.2 & 2.4 \\
\hline & & 1995 & 13.7 & 203 & 271 & 34 & 10.2 & 51.5 & 62.2 & 5.4 & 11.9 & 12.4 & 16.4 & 2.0 \\
\hline \multirow[t]{2}{*}{ ХCAT.CTA155 } & 7BL & 1994 & 15.8 & 248 & 353 & 52 & 18.1 & 43.6 & $\mathbf{5 9 . 9}$ & 8.1 & 15.1 & 11.2 & 16.1 & 2.4 \\
\hline & & 1995 & 13.2 & 201 & 268 & 34 & 12.0 & 50.4 & 62.0 & 5.8 & 11.3 & 12.4 & 16.3 & 2.0 \\
\hline \multirow[t]{2}{*}{ Xbarc182 } & 7BL & 1994 & 13.3 & 255 & 347 & 46 & 15.0 & 45.0 & 59.5 & 7.3 & 12.3 & 11.5 & 15.8 & 2.1 \\
\hline & & 1995 & 14.4 & 201 & 272 & 35 & 12.8 & 51.0 & 63.0 & 6.0 & 12.0 & 12.3 & 16.4 & 2.0 \\
\hline \multirow{2}{*}{ XCAG.CGAT70 } & 2B & 1994 & 11.1 & 256 & 342 & 43 & 11.2 & 45.5 & 58.1 & 6.3 & 9.1 & 11.7 & 15.4 & 1.9 \\
\hline & & 1995 & 9.9 & 204 & 263 & 30 & 12.4 & 50.2 & 62.3 & 6.0 & 9.3 & 12.4 & 16.0 & 1.8 \\
\hline \multirow{2}{*}{ Xbarc167 } & 2B & 1994 & 11.0 & 259 & 342 & 42 & 10.5 & 46.3 & 58.2 & 6.0 & 8.9 & 11.8 & 15.4 & 1.8 \\
\hline & & 1995 & 14.8 & 198 & 269 & 35 & 18.0 & 49.1 & 63.1 & 7.0 & 13.7 & 12.1 & 16.3 & 2.1 \\
\hline Xwmc344 & 2B & 1994 & 10.9 & 265 & 347 & 50 & 8.4 & 47.6 & $\mathbf{5 8 . 4}$ & 5.4 & 10.7 & 12.0 & 15.9 & 2.0 \\
\hline & & 1995 & 9.7 & 212 & 269 & 29 & 9.1 & 52.6 & 62.7 & 5.0 & 9.6 & 92.8 & 16.4 & 1.8 \\
\hline XAGC.TGC135 & 2B & 1994 & 9.0 & 271 & 354 & 41 & 7.1 & 48.4 & $\mathbf{5 9 . 0}$ & 5.3 & 6.0 & 12.4 & 15.7 & 1.6 \\
\hline & & 1995 & 5.0 & 215 & 258 & 22 & 5.2 & 53.0 & 60.9 & 4.0 & 5.5 & 13.0 & 15.8 & 1.4 \\
\hline XCAT.CGTA150 & 2B & 1994 & 5.9 & 274 & 337 & 31 & 5.8 & 48.2 & 57.3 & 4.5 & 4.9 & 12.5 & 15.2 & 1.4 \\
\hline & & 1995 & 11.5 & 206 & 270 & 32 & 12.2 & 51.2 & 63.1 & 5.9 & 12.3 & 12.4 & 16.6 & 2.1 \\
\hline XGCTG.CGAT7 & 2B & 1994 & 4.3 & 274 & 329 & 28 & & & & & & & & \\
\hline & & 1995 & 9.2 & 208 & 264 & 28 & & & & & & & & \\
\hline ХCAT.CGTA146 & 2B & 1994 & 3.9 & 275 & 325 & 25 & & & & & & & & \\
\hline & & 1995 & 9.1 & 205 & 262 & 29 & & & & & & & & \\
\hline Xbarc32 & 7BL & 1994 & & & & & 8.1 & 45.5 & 56.3 & 5.4 & & & & \\
\hline & & 1995 & & & & & 3.9 & 52.2 & 59.0 & 3.4 & & & & \\
\hline XCATG.CGTA152 & 2B & 1994 & & & & & 4.3 & 48.4 & 56.2 & 3.9 & & & & \\
\hline & & 1995 & & & & & 7.1 & 52.4 & 61.7 & 4.6 & & & & \\
\hline
\end{tabular}

SSR markers, Xbarc167, Xbarc18, and Xwmc344, were all previously mapped on the proximal end of $2 \mathrm{BS}$ (Somers et al., 2004). QLr.osu-2B explained 18.8, 16.6, and $16.0 \%$ of the phenotypic variance for AUDPC, FS and IR in 1994, and $13.4,15.2$, and $13.6 \%$ of the phenotypic variance in 1995, respectively.

Since the known slow leaf-rusting resistance genes, Lr34 and Lr46, were previously mapped on 7DS and $1 \mathrm{~B}$, respectively, $Q L$ r.osu- $2 B$ may be a new QTL for slow leaf-rusting resistance. Application of this QTL in wheat breeding should diversify the slow leaf-rusting sources and be helpful for breeding durable leaf rust resistant cultivars. It is interesting to note that Nelson et al. (1995) detected a QTL on chromosome 2BS in a synthetic wheat, and Messmer et al. (2000) also found a QTL on $2 \mathrm{BS}$ explaining $8 \%$ of the phenotypic variance in one of four environments.
Young (1996) hypothesized that quantitative resistance loci are simply variants of qualitative resistance loci that have been (partially) overcome by their respective pathogen. Among the known major leaf rust resistance genes, Lr13, Lr16, Lr23, and Lr35 were mapped on chromosome 2B (McIntosh et al., 1995). Lr13, Lr23, and Lr35 are adult plant resistance (APR) genes. Among them, $\operatorname{Lr} 35$ was mapped near the centromere (Seyfarth et al., 1999), where $Q L$ r.osu- $2 B$ was tentatively located. However, Seyfarth et al. used RFLP rather than SSR markers to map $L r 35$, and we cannot further compare Lr35 with $Q L$ r.osu- $2 B$ at this time. One alternative way is to test the race-specificity of the QTL by inoculating the RILs with specific races. A previous study indicated that disease resistance QTL showed distinctly different effects against different races in tomato (LeonardsSchippers et al., 1994).

Table 3. Mean allelic effects of significant molecular markers on chromosome 2D on infection duration (ID) in the RIL population derived from CI 13227/Suwon 92 in 1994 and 1995.

\begin{tabular}{|c|c|c|c|c|c|c|}
\hline \multirow[b]{2}{*}{ Marker } & \multirow{2}{*}{$\begin{array}{c}\text { Chromosome } \\
\text { location }\end{array}$} & \multirow[b]{2}{*}{ Year } & \multirow{2}{*}{$\begin{array}{l}R^{2} \\
(\%)\end{array}$} & \multicolumn{2}{|c|}{ Allele mean } & \multirow{2}{*}{$\begin{array}{c}\text { Additive } \\
\text { effect }\end{array}$} \\
\hline & & & & CI 13227 & Suwon 92 & \\
\hline & & & & & 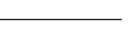 & \\
\hline \multirow[t]{2}{*}{ XGCTG.CGCT118 } & 2D & 1994 & 27.9 & 24.4 & 21.4 & 1.5 \\
\hline & & 1995 & 25.3 & 18.7 & 17.6 & 0.5 \\
\hline \multirow[t]{2}{*}{ XGCTG.CGCT60 } & 2D & 1994 & 23.7 & 24.1 & 21.3 & 1.4 \\
\hline & & 1995 & 19.6 & 18.6 & 17.6 & 0.5 \\
\hline \multirow{2}{*}{ Xbarc95 } & $2 D$ & 1994 & 6.6 & 23.6 & 22.2 & 0.7 \\
\hline & & 1995 & 13.8 & 18.6 & 17.8 & 0.4 \\
\hline \multirow[t]{2}{*}{ ХCAT.CGTA237 } & 2D & 1994 & 5.5 & 23.4 & 22.0 & 0.7 \\
\hline & & 1995 & 6.8 & 18.4 & 17.8 & 0.3 \\
\hline \multirow{2}{*}{ ХTGC.CTA208 } & 2D & 1994 & 4.0 & 23.2 & 22.0 & 0.6 \\
\hline & & 1995 & 8.0 & 18.4 & 17.7 & 0.3 \\
\hline
\end{tabular}




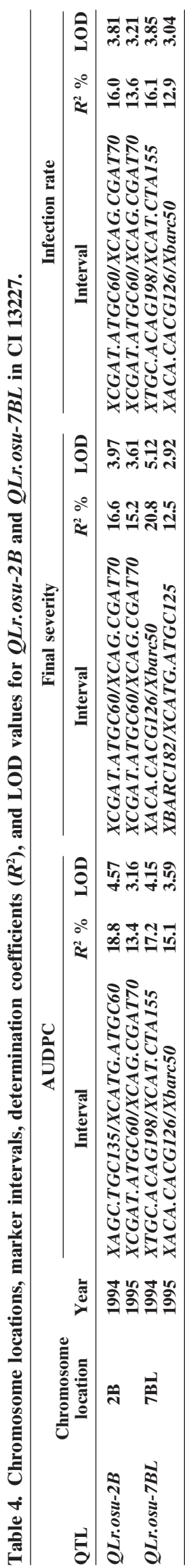

A:

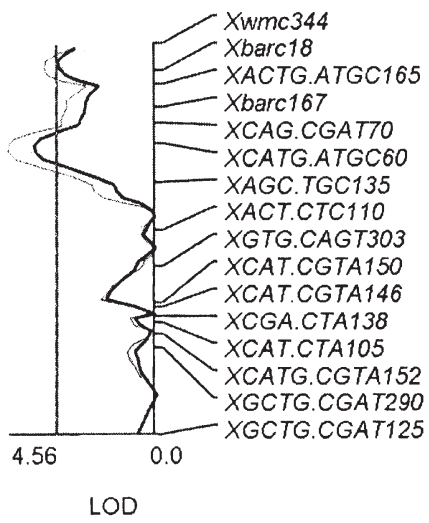

B:

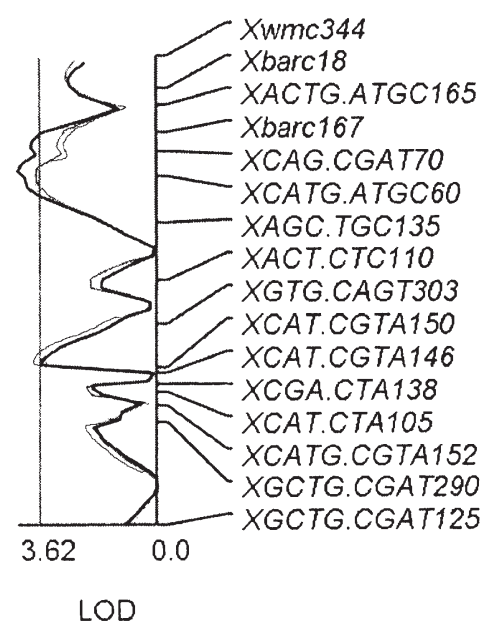

Fig. 2. Likelihood plots of the QTL QLr.osu-2B for AUDPC (solid curves), final severity (bold curves), and infection rate (dotted curves) measured in 1994 (A) and 1995 (B). The vertical line shows the LOD value of 3.0. The number under the horizontal line represents the highest LOD value.

Another QTL, designated as $Q L$ r.osu-7BL, was also detected in both years. This QTL was putatively assigned to 7BL according to the location of the linked SSR markers Xbarc50, Xbarc1073, Xbarc182, and Xbarc32. These SSRs were previously mapped on 7BL, though Xbarc32 was also mapped on 5BL (http://www.scabusa.org/pdfs/BARC maps_011106.pdf; verified 18 November 2004). The LOD score peaks of this QTL were located between AFLP marker XTGC.ACAG198 and SSR marker Xbarc50, varying among traits and environments (Fig. 3). It explained $17.2,20.8$, and $16.1 \%$ of the phenotypic variance for AUDPC, FS, and IR in 1994, and 15.1, 12.5, and $12.9 \%$ in 1995 (Table 4). Further fine mapping of this region to 
A

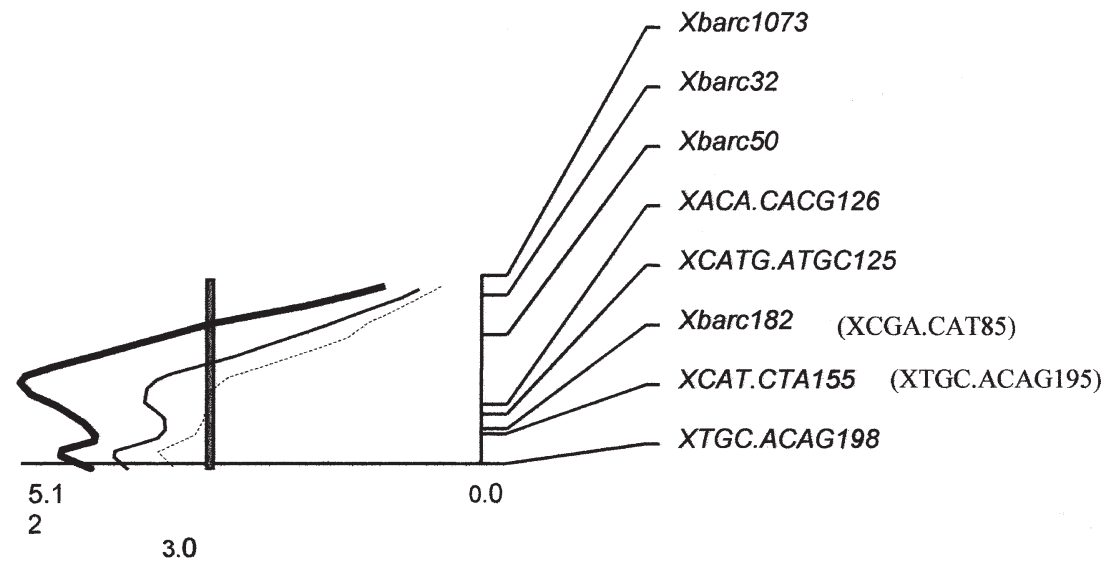

B:

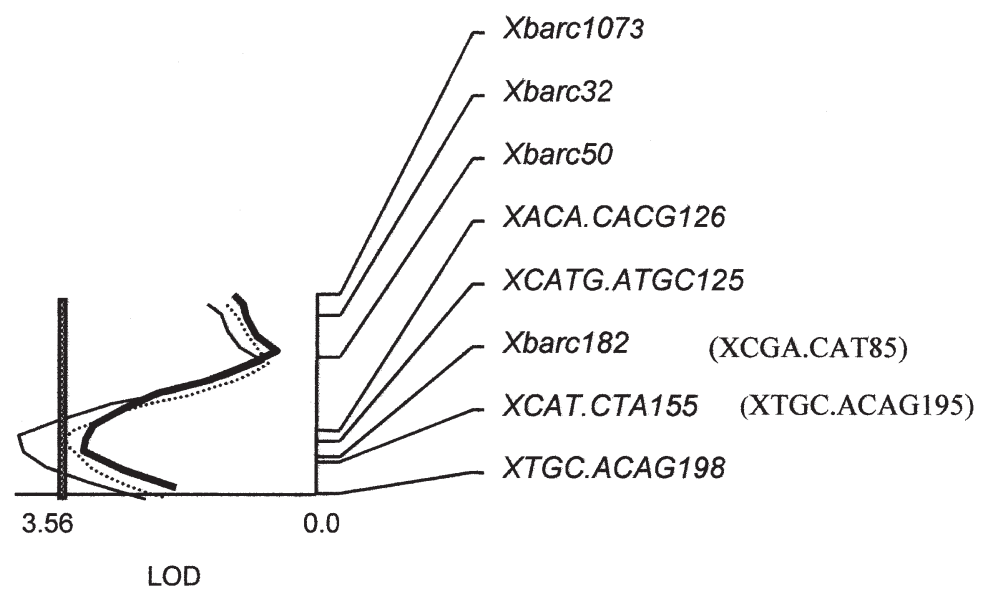

Fig. 3. Likelihood plots of the QTL QLr.osu-7BL for AUDPC (solid curves), final severity (bold curves), and infection rate (dotted curves) in 1994 (A) and 1995 (B). The vertical line shows the LOD value of 3.0. The number under the horizontal line represents the highest LOD value.

pinpoint $Q L$ r.osu-7BL would be helpful for map-based cloning or MAS of this QTL.

The QTL on 2DS, designated as QLrid.osu-2DS, was only associated with leaf rust infection duration (ID). All SSR markers linked to this QTL were previously mapped on the short arm of chromosome 2D (Somers et al., 2004; http://www.scabusa.org/pdfs/BARC_maps_ 011106.pdf; verified 10 November 2004). This QTL was located in the interval between SSR marker Xgwm261 and AFLP marker XGCTG.CGCT118 with a LOD score of 6.99 and 5.88 for ID in 1994 and 1995, respectively (Fig. 4). This QTL was quite stable, and explained 26.4 and $21.5 \%$ of the phenotypic variance in 1994 and 1995 , respectively. However, the positions of this QTL varied slightly between 1994 and 1995. The LOD score plot of this QTL peaked $1.3 \mathrm{cM}$ away from XGCTG.CGCT118 in 1994, but on the exact location of XGCTG.CGCT118 in 1995. Longer ID was inherited from CI 13227 and associated with later heading date $(r=0.69 p<0.01)$. The heading date of CI 13227 was seven days later than that of Suwon 92 in 1994 and 12 d later in 1995. Since ID was negatively correlated with AUDPC, FS, and IR, the RILs with longer ID showed a higher level of rust resistance. The more resistant the RILs, the later their leaves senesced.

\section{Future Improvement of Slow-Rusting Resistance}

On the basis of genetic correlation estimates, several slow-rusting components were described to be either tightly linked or under pleiotropic genetic control (Singh et al., 1991; Das et al., 1993). The two QTL for AUDPC

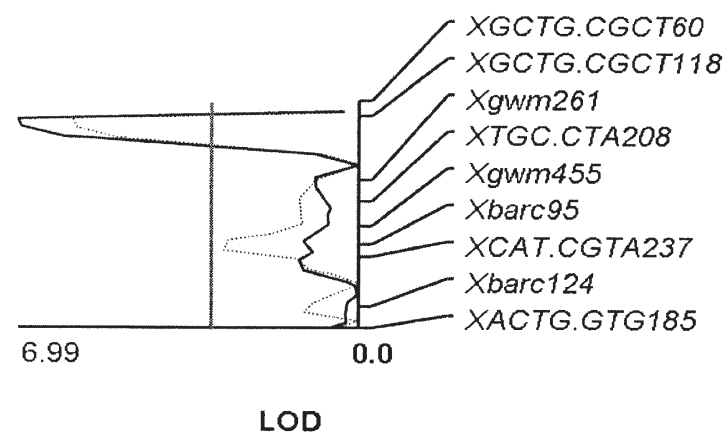

Fig. 4. Likelihood plots of a QTL for leaf rust infection duration in 1994 (solid curve) and 1995 (dot curve). The vertical line shows the LOD value of 3.0. The number under the horizontal line represents the highest $L O D$ value. 
Table 5. Allelic substitution effects of SSR markers, Xbarc18 and Xbarc182, on leaf rust final severity (FS), AUDPC value, and infection rate (AUDPC/day).

\begin{tabular}{|c|c|c|c|c|c|c|}
\hline \multirow[b]{2}{*}{ Genotype $†$} & \multicolumn{3}{|c|}{1994} & \multicolumn{3}{|c|}{1995} \\
\hline & FS (\%) & AUDPC & AUDPC/day & FS (\%) & AUDPC & AUDPC/day \\
\hline $\begin{array}{l}\mathbf{Q}^{1} \mathbf{Q}^{1} \mathbf{Q}^{2} \mathbf{Q}^{2} \\
\mathbf{Q}^{1} \mathbf{Q}^{1} \mathbf{q}^{2} \mathbf{q}^{2} \\
\mathbf{q}^{1} \mathbf{q}^{1} \mathbf{Q}^{2} \mathbf{Q}^{2} \\
\mathbf{q}^{1} \mathbf{q}^{1} \mathbf{q}^{2} \mathbf{q}^{2}\end{array}$ & $\begin{array}{l}40.0 \mathrm{a} \div \\
52.7 \mathrm{~b} \\
54.9 \mathrm{~b} \\
64.5 \mathrm{c}\end{array}$ & $\begin{array}{l}217.8 \text { a } \\
319.7 \text { b } \\
302.6 \text { b } \\
385.1 \text { c }\end{array}$ & $\begin{array}{r}9.7 \mathrm{a} \\
14.4 \mathrm{~b} \\
14.0 \mathrm{~b} \\
17.5 \mathrm{c}\end{array}$ & $\begin{array}{l}48.1 \mathrm{a} \\
56.3 \mathrm{~b} \\
54.3 \mathrm{~b} \\
67.5 \mathrm{c}\end{array}$ & $\begin{array}{l}180.9 \text { a } \\
234.5 \text { b } \\
237.4 \text { b } \\
293.1 \text { c }\end{array}$ & $\begin{array}{l}11.0 \mathrm{a} \\
14.7 \mathrm{~b} \\
14.4 \mathrm{~b} \\
17.6 \mathrm{c}\end{array}$ \\
\hline
\end{tabular}

$\dagger Q^{1}$ and $Q^{2}$ represent CI 13227 allele at Xbarc18 and Xbarc182 locus, respectively. Likewise, $q^{1}$ and $q^{2}$ represent Suwon 92 allele at $X b a r c 18$ and $X b a r c 182$ locus, respectively.

† Means followed by different letters are significantly different at $\boldsymbol{P}=\mathbf{0 . 0 5}$.

detected in this study were coincident with QTL for FS and IR. Coincident QTL support the observed pattern of high phenotypic correlations for these traits $(r=$ $0.93-0.98)$. Autocorrelations may also exist among the three parameters because calculations of AUDPC and infection rate were based on leaf rust severity. Both the QTL analysis and correlation analysis suggest that AUDPC, FS, and IR are under the same genetic control and reflect different aspects of the same process, slow leaf-rusting. Hence, we find it reasonable to select for slow-rusting genotypes on the basis of final severity only as suggested by Das et al. (1993).

Both QTL for slow leaf-rusting detected in our study, QLr.osu-2B and QLr.osu-7BL, were also coincident with QTL identified previously for latent period (Xu et al., 2005). This apparent pleiotropic relationship is similar to the pleiotropic effect of Lr34 on the components of slow-rusting resistance, including a prolonged latent period, and reduced receptivity and uredinium size (Singh and Huerta-Espino, 2003). Rubiales and Niks (1995) also reported that Lr34 increased latent period and decreased infection frequency. However, $\mathrm{Xu}$ et al. (2005) identified a major QTL for prolonged latent period of Puccinia triticina on chromosome 2DS, and this QTL was not significantly associated with AUDPC, FS, and IR. This suggests a different genetic mechanism for defense against Puccinia triticina.

Although the QTL on chromosome 2B and 7BL were documented before (Nelson et al., 1995; William et al., 1997; Messmer et al., 2000; Faris et al., 1999), PCR-based markers associated with these QTL are still rare. In this study, we identified AFLP and SSR markers closely linked to these QTL. The application of AFLP markers in breeding programs still poses technical difficulties. The further conversion of AFLP markers flanking these QTL, such as XCAG.CGAT70, XCATG.ATGC60, XCAT. $C G T A 150$, and $X T G C . A C A G 198$, into STS markers will greatly facilitate the introgression of these QTL into other cultivars. As an alternative, SSR markers Xbarc167 and Xbarc18 were also closely associated with $Q L$ r.osu-2B, while $X$ barc182 was tightly linked to $Q L$ r.osu- $7 B L$. They have the potential to be directly used in MAS for the corresponding QTL. Further analysis showed that RILs with resistant alleles at both Xbarc18 and Xbarc182 loci were significantly more resistant than those with only one or no resistant allele at the corresponding locus (Table 5). Also, the effects of $Q L$ r.osu- $2 B$ and $Q L$ r.osu- $7 B L$ were similar since RILs with only one of the two resistant alleles had similar AUDPC, FS, and IR in both years. This is in agreement with the QTL mapping results. Thus we believe that significant genetic gains can be achieved by introgressing $Q L$ r.osu- $2 B$ and $Q L$ r.osu-7BL into other cultivars by MAS.

Considering the high adaptability and the rapid distribution of virulent isolates of Puccinia triticina over long distances, the best strategy for breeding durable leaf rust resistant cultivars should be the combination of race-specific resistance gene(s) with race nonspecific resistance gene(s) or QTL. In fact, most of the identified durable leaf rust resistant cultivars carry $L r 34$, a slow leafrusting resistance gene, and other race-specific gene(s). The South American cultivar Frontana, which was regarded as one of the best sources of durable resistance to leaf rust, carries Lr34, Lr13, and LrT3 (Dyck and Samborski, 1982). Chinese Spring, a popular wheat cultivar whose resistance to leaf rust has lasted for about a century in North America (Kolmer, 1996), carries Lr34, Lr12 (Dyck, 1991), and Lr31 genes for leaf rust resistance (Singh and McIntosh, 1984). However, this strategy is not practical in traditional breeding programs because of the time-consuming process involving complex inoculation tests and extensive disease measurements, but is feasible when linked markers are available. Molecular markers linked to race-specific and slow leafrusting resistance genes, including $L r 1, L r 3, L r 9, L r 10$, Lr13, Lr19, Lr23, Lr24, Lr27, Lr28, Lr31, Lr34, Lr35, and Lr47 (Gupta et al., 1999; Langridge et al., 2001), have been identified. Some of these markers are STS markers that can be directly used in MAS (Naik et al., 1998; Seyfarth et al., 1999; Helguera et al., 2000), while others have the potential to be converted into STS markers. These markers, and the three identified herein (Xbarc18, Xbarc167, and Xbarc182), are valuable for breeding durable leaf rust resistant cultivars by combining race-specific and race-nonspecific resistance genes.

\section{REFERENCES}

Bjarko, M.E., and R.E. Line. 1988a. Heritability and number of genes controlling leaf rust resistance in four cultivars of wheat. Phytopathology 78:456-461.

Bjarko, M.E., and R.F. Line. 1988b. Quantitative determination of the gene action of leaf rust resistance in four cultivars of wheat, Triticum aestivum. Phytopathology 78:451-456.

Caldwell, R.M., J.J. Roberts, and Z. Eyal. 1970. General resistance ("slow-rusting") to Puccinia recondita f. sp. tritici in winter and spring wheats. Phytopathology 60:1287 (abstract).

Das, M.K., S. Rajaram, C.C. Mundt, W.E. Kronstad, and R.P. Singh. 1992. Inheritance of slow-rusting resistance in wheat. Crop Sci. 32:1452-1456.

Das, M.K., S. Rajaram, C.C. Mundt, W.E. Kronstad, and R.P. Singh. 1993. Associations and genetics of three components of slow-rusting in leaf rust in wheat. Euphytica 68:99-109. 
Dyck, P.L. 1991. Genetics of leaf rust resistance in 'Chinese Spring' and 'Sturdy' cultivars. Crop Sci. 31:309-311.

Dyck, P.L. 1977. Genetics of leaf rust reactions in three introductions of common wheat. Can. J. Genet. Cytol. 19:711-716.

Dyck, P.L., and D.J. Samborski. 1982. The inheritance of resistance to Puccinia recondita in a group of common wheat cultivars. Can. J. Genet. Cytol. 24:273-278.

Faris, J.D., W.L. Li, D.J. Liu, P.D. Chen, and B.S. Gill. 1999. Candidate gene analysis of quantitative disease resistance genes. Theor. Appl. Genet. 98:219-225.

Gupta, P.K., R.K. Varshney, P.C. Sharma, and B. Ramesh. 1999. Molecular markers and their applications in wheat breeding. Plant Breed. 118:369-390.

Helguera, M., I.A. Khan, and J. Dubcovsky. 2000. Development of PCR markers for wheat leaf rust resistance gene Lr47. Theor. Appl. Genet. 101:625-631.

Jeger, M.J., and S.L.H. Viljanen-Rollinson. 2001. The use of the area under the disease-progress curve (AUDPC) to assess quantitative disease resistance in crop cultivars. Theor. Appl. Genet. 102:32-40.

Kolmer, J.A. 1996. Genetics of resistance to wheat leaf rust. Annu. Rev. Phytopathol. 34:435-455.

Kosambi, D.D. 1944. The estimation of map distances from recombination values. Ann. Eugen. 12:172-175.

Kuhn, R.C., H.W. Ohm, and G. Shaner. 1978. Slow leaf-rusting resistance in wheat against twenty-two isolates of Puccinia recondita. Phytopathology 68:651-656.

Lander, E.S., P. Green, J. Abrahamson, A. Barlow, M.J. Daly, S.E. Lincoln, and I. Newburg. 1987. Mapmaker: An interactive computer package for constructing primary genetic linkage maps of experimental and natural populations. Genomics 1:174-181.

Langridge, P., E.S. Lagudah, T.A. Holton, R. Appels, P.J. Sharp, and K.J. Chalmers. 2001. Treads in genetic and genome analysis in wheat: A review. Aust. J. Agric. Res. 52:1043-1077.

Leonards-Schippers, C., W. Gieffers, R. Schaufer-Pregl, E. Ritter, and S.J. Knapp. 1994. Quantitative resistance to Phytophthora infestans in potato: A case study of QTL mapping in an allogamous plant species. Genetics 137:67-77.

McDonald, B.A., and C. Linde. 2002. Pathogen population genetics, evolutionary potential, and durable resistance. Annu. Rev. Phytopathol. 40:349-379.

McIntosh, R.A. 1992. Close genetic linkage of genes conferring adultplant resistance to leaf rust and stripe rust of wheat. Plant $\mathrm{Pa}$ thol. 41:523-527.

McIntosh, R.A., C.R. Wellings, and R.F. Park. 1995. Wheat rust: An atlas of resistance genes. CSIRO Australia and Kluwer Academic Publ., Dordrecht, the Netherlands.

Messmer, M.M., S. Seyfarth, M. Keller, G. Schachermayr, M. Winzeler, S. Zanetti, C. Feuillet, and B. Keller. 2000. Genetic analysis of durable leaf rust resistance in winter wheat. Theor. Appl. Genet. 100:419-431.

Michelmore, R.W., I. Paran, and R.V. Kesseli. 1991. Identification of markers lined to disease-resistance genes by bulked segregant analysis: A rapid method to detect markers in specific genomic regions by using segregating populations. Proc. Natl. Acad. Sci. USA 88:9828-9832.

Murray, M.G., and W.F. Thompson. 1980. The isolation of high molecular weight plant DNA. Nucleic Acids Res. 8:4321-4325.

Naik, S., K.S. Gill, V.S. Prakasa Rao, V.S. Gupta, S.A. Tamhankar, S. Pujar, B.S. Gill, and P.K. Ranjekar. 1998. Identification of a STS marker linked to the Aegilops speltoides-derived leaf rust resistance gene $\operatorname{Lr} 28$ in wheat. Theor. Appl. Genet. 97:535-540.

Nelson, J.C. 1997b. Qgene: Software for maker-based genomic analysis and breeding. Mol. Breed. 3:239-245.

Nelson, J.C., R.P. Singh, E. Autrique, and M.E. Sorrells. 1997a. Mapping genes conferring and suppressing leaf rust resistance in wheat. Crop Sci. 37:1928-1935.

Nelson, J.C., M.S. Sorrells, A.E. Van Deynze, Y.H. Liu, E. Autrique,
M. Atkinson, P. Leroy, M. Bernard, J.D. Faris, and J.A. Anderson. 1995. Molecular mapping of wheat. Major genes and rearrangements in homoeologous group 4, 5, and 7. Genetics 141:721-731.

Parlevliet, J.E. 1979. Components of resistance that reduce the rate of epidemic development. Annu. Rev. Phytopathol. 17:203-222.

Peterson, R.F., A.B. Campbell, and A.E. Hannah. 1948. A diagrammatic scale for estimating rust severity on leaves and stems of cereals. Can. J. Res. Sect C. Bot. Sci. 26:496-500.

Roelfs, A.P. 1988. Resistance to leaf and stem rust in wheat. p. 10-22. In Breeding strategies for resistance to the rusts of wheat. Edited by N.W. Simmonds, and S.Rajaram. Centro Internacional de Mejoramiento de Maiz y Trigo (CIMMYT), Mexico D.F., Mexico.

Rubiales, D., and R.E. Niks. 1995. Characterization of Lr34, a major gene conferring nonhypersensitive resistance to wheat leaf rust. Plant Dis. 79:1208-1212.

Seyfarth, R., C. Feuillet, G. Schachermayr, M. Winzeler, and B. Keller. Development of a molecular marker for adult plant leaf rust resistance gene Lr35 in wheat. 1999. Theor. Appl. Genet. 99:554-560.

Schnursch, T., S. Pailard, A. Schori, M. Messmer, G. Schachermayr M. Winzeler, and B. Keller. 2004. Dissertation of quantitative and durable leaf rust resistance in Swiss winter wheat reveals a major resistance QTL in the Lr34 chromosomal region. Theor. Appl. Genet. 108:477-482.

Shaner, G., G. Buechley, and W.E. Nyquist. 1997. Inheritance of latent period of Puccinia recondita in wheat. Crop Sci. 37:748-756.

Shaner, G., and R.E. Finney. 1980. New sources of slow leaf-rusting resistance in wheat. Phytopathology 70:1183-1186.

Singh, R.P. 1992. Association between gene Lr34 for leaf rust resistance and leaf tip necrosis in wheat. Crop Sci. 32:874-878.

Singh, R.P. 1993. Genetic association of gene Bdv1 for tolerance to barley yellow dwarf virus with genes Lr34 and Yr18 for adult plant resistance to rusts in bread wheat. Plant Dis. 77:1103-1106.

Singh, R.P., and J. Huerta-Espino. 2003. Effect of leaf rust resistance gene Lr34 on components of slow-rusting at seven growth stages in wheat. Euphytica 129:371-376.

Singh, R.P., and R.A. McIntosh. 1984. Complementary genes for reaction to Puccinia recondita tritici in Triticum aestivum. 1. Genetic and linkage studies. Can. J. Genet. Cytol. 26:723-735.

Singh, R.P., A. Mujeeb-Kazi, and J. Huerta-Espino. 1998. Lr46: A gene conferring slow-rusting resistance to leaf rust in wheat. Phytopathology 88:890-894.

Singh, R.P., T.S. Pane, and S. Raharam. 1991. Characterization of variability and relationships among components of partial resistance to leaf rust in CIMMYT bread wheat. Theor. Appl. Genet. 82:674-680.

Somers, D.J., P. Isaac, and K. Edwards. 2004. A high-density microsatellite consensus map for bread wheat (Triticum aestivum). Theor. Appl. Genet. 109:1105-1114.

Suenaga, K., R.P. Singh, J. Huerta-Espino, and H.M. William. 2003. Microsatellite markers for genes $L r 34 / Y r 18$ and other quantitative trait loci for leaf rust and stripe rust resistance in bread wheat. Phytopathology 93:881-890.

Wilcoxson, R.D., B. Skovmand, and A.H. Atif. 1975. Evaluation of wheat cultivars for ability to retard development of stem rust. Annu. Rev. Biol. 80:275-281.

William, H.M., D. Hosington, R.P. Singh, and D. Gonzalez-Leon. 1997. Detection of quantitative trait loci associated with leaf rust resistance in bread wheat. Genome 40:253-260.

William, M., R.P. Singh, J. Huerta-Espino, S. Ortiz Islas, and D. Hoisington. 2003. Molecular marker mapping of leaf rust resistance gene Lr46 and its association with stripe rust resistance gene $\mathrm{Yr} 29$ in wheat. Phytopathology 93:153-159.

Xu, X.-Y., G.-H. Bai, B.F. Carve, G. Shaner, and R. Hunger. 2005. Mapping of QTL prolonging latent period of Puccinia triticina infection in wheat. Theor. Appl. Genet. (in press).

Young, N.D. 1996. QTL mapping and quantitative disease resistance in plants. Annu. Rev. Phytopathol. 34:479-501. 